\title{
Perceptions of medical students about Pathology training
}

\author{
Shubha P Bhat ${ }^{1}$, Laxmi Cheriyanath ${ }^{2}$, Malavika Nair ${ }^{2}$, Mahendran M Nair ${ }^{2}$ \\ ${ }^{1}$ Department of Pathology, KS Hegde Medical Academy, Karnataka, India \\ ${ }^{2} M B B S$ student, KS Hegde Medical Academy, Karnataka, India
}

\section{Keywords: \\ Medical students; \\ Pathology; \\ Perception; \\ Teaching-learning methods; \\ Undergraduate;}

\begin{abstract}
Background: An understanding of pathology is the foundation for good clinical practice. Pathology is a vast subject with limited teaching hours. Understanding the students' perspectives is essential for making new roadmaps for teaching.
\end{abstract}

Materials and Methods: This is a survey conducted on medical students who have completed secondyear. They were asked to answer a pre-validated questionnaire regarding the teaching-learning and assessment methods followed in the pathology department.

Results: Of the 152 students, the majority (84\%) of students perceived pathology as an interesting subject. Most $(87 \%)$ of the students agreed that the integration of pathology teaching with clinical training helped in a better understanding of diseases. Many (54\%) students found general pathology to be difficult than systemic pathology. Most of the students agreed that lectures and demonstrations are taken in ways that stimulate interest in the subject. The majority were of the consensus that appropriate clinical correlation was done during lectures along with highlighting essential points. Regarding the teaching tools used in pathology, $55 \%$ of the students preferred teaching by PowerPoint presentation only while $45 \%$ preferred a combined blackboard and PowerPoint presentation. Many considered that integrated teaching helps in a better understanding of the subject. The formative method of assessment was favoured by most of the students. Our study showed that $74 \%$ of students find multiple-choice questions as an effective assessment tool.

Conclusion: As the new curriculum for competency-based medical education is through, the result of our study is an encouragement to be prepared for the same.

\section{Correspondence:}

Dr. Shubha P Bhat, MD

Department of Pathology

KS Hegde Medical Academy, Mangalore, Karnataka, India

ORCID ID: 0000-0003-4283-2836

Email:bhatshubha_257@rediffmail.com

Reveived : May $10^{\text {th }} 2020$; Accepted : December $16^{\text {th }} 2020$

Citation: Bhat SP, Cheriyanath L, Nair M, Nair MM. Perceptions of Medical students about Pathology training. Journal of Pathology of Nepal. 2021;11(2): 1830-4. DOI: 10.3126/jpn. v11i2.28916

Copyright: This is an open-access article distributed under the terms of the Creative Commons Attribution 4.0 International License, which permits unrestricted use, distribution, and reproduction in any medium, provided the original author and source are credited.

\section{INTRODUCTION}

The second year is crucial for Bachelor of Medicine and Bachelor of Surgery (MBBS) students as they are introduced to human disease processes during this period. Pathology is a medical specialty that provides a scientific foundation for medical practice, where the pathogenesis of diseases is taught to enable students to understand concepts of medicine. ${ }^{1}$ Pathology learning has changed from seeing mounted specimens in pathology museums and real organs at autopsy to looking at digital images and simulation. ${ }^{2}$ It is believed that students, after preclinical years, should be motivated to learn pathology and its links to clinical 
medicine. The enthusiasm and knowledge of pathology as a career depends on the impact with which the faculty has delivered the concepts, aroused interest among the students to study pathology. ${ }^{3}$ Regular reviewing of teaching-learning methods of teachers is necessary for improvement. Students' feedback is a relatively reliable method of assessing the teaching-learning process and its effectiveness. It is also very convenient, inexpensive, and easy to obtain. ${ }^{4}$ This study is aimed at understanding students' perspectives regarding pathology subjects and about the effectiveness of various teaching-learning methods currently used by the faculty of the pathology department.

\section{MATERIALS AND METHODS}

The present study was conducted on 152 students of a medical college of Mangaluru, India, who have completed second-year MBBS. Approval from the institutional ethics committee was obtained. After informed consent, students were asked to answer the structured pre-validated questionnaire regarding the teaching-learning methods and assessment methods followed in the pathology department. The survey included questions on teaching-learning and evaluation methods. Participants were asked to answer these questions on a five-point Likert scale as strongly agree, agree, neutral, disagree, and strongly disagree. The data collected was summarized and represented as frequency and percentage.

\section{RESULTS}

We conducted the study on 152 students who had recently completed their second-year MBBS and were promoted to the third year. All 152 students answered all 17 questions.

The majority of students (44\%) agreed that pathology is an interesting subject. Most of the students (60\%) strongly agreed that pathology helped in clinical training, while 34\% agreed to it. The results of the perception of students about pathology and teaching methodology are given in Table 1 and 2.

Regarding the teaching tools used in Pathology, 55\% of our students preferred teaching by PowerPoint presentation (PPP) only, while $45 \%$ preferred combined blackboard and PPP. About the effectiveness of integrated teaching, $31 \%$ of the students strongly agreed that it is effective, and 33\% agreed to it too. The neutral opinion was seen in $22 \%$ of students

Regarding the mode of assessment, $22 \%$ of the students strongly agreed that the assessments conducted in the form of the formative evaluation served the purpose of analyzing cognitive skill (Knowledge), and 46\% agreed to it too. While neutral opinion was given by $24 \%$ of students, $5 \%$ disagreed, and 3\% strongly disagreed with it. The majority of the students consider MCQ as an effective tool in assessing the knowledge of a student (34\% strongly agree

Table 1: Perceptions about pathology

\begin{tabular}{|c|c|c|c|c|c|}
\hline Perception about Subject & Strongly Agree & Agree & Neutral & Disagree & Strongly Disagree \\
\hline Is pathology an interesting subject? & $40 \%$ & $44 \%$ & $14 \%$ & $2 \%$ & - \\
\hline $\begin{array}{l}\text { Does knowledge of pathology help in clinical } \\
\text { training? }\end{array}$ & $60 \%$ & $34 \%$ & $4 \%$ & $2 \%$ & - \\
\hline $\begin{array}{l}\text { Does the integration of pathology teaching with } \\
\text { clinical training will help in better understanding } \\
\text { of diseases? }\end{array}$ & $47 \%$ & $40 \%$ & $11 \%$ & $2 \%$ & - \\
\hline $\begin{array}{l}\text { Is general pathology more difficult to understand } \\
\text { than systemic pathology? }\end{array}$ & $22 \%$ & $32 \%$ & $31 \%$ & $5 \%$ & $10 \%$ \\
\hline
\end{tabular}

Table 2: Perceptions about pathology

\begin{tabular}{|c|c|c|c|c|c|}
\hline Teaching methodology & Strongly Agree & Agree & Neutral & Disagree & Strongly Disagree \\
\hline $\begin{array}{l}\text { Do lectures and demonstrations taken in a way } \\
\text { that stimulated interest in the subject? }\end{array}$ & $6 \%$ & $34 \%$ & $32 \%$ & $13 \%$ & $15 \%$ \\
\hline $\begin{array}{l}\text { Were the delivery and pace of lectures suitable to } \\
\text { the level of your understanding in the class? }\end{array}$ & $12 \%$ & $41 \%$ & $36 \%$ & $11 \%$ & - \\
\hline $\begin{array}{l}\text { Does the teaching of clinical correlation wherever } \\
\text { relevant is been done in pathology lectures? }\end{array}$ & $18 \%$ & $46 \%$ & $27 \%$ & $7 \%$ & $2 \%$ \\
\hline $\begin{array}{l}\text { Did the highlighting of important points during } \\
\text { lectures help you for further study in each topic? }\end{array}$ & $26 \%$ & $45 \%$ & $23 \%$ & $6 \%$ & - \\
\hline $\begin{array}{l}\text { Did the teachers encourage students to ask } \\
\text { questions? }\end{array}$ & $23 \%$ & $37 \%$ & $29 \%$ & $11 \%$ & - \\
\hline $\begin{array}{l}\text { Does the integrated teaching method help in a } \\
\text { better understanding of the subject? }\end{array}$ & $31 \%$ & $33 \%$ & $22 \%$ & $10 \%$ & $4 \%$ \\
\hline
\end{tabular}


Table 3: Mode of assessment

\begin{tabular}{|c|c|c|c|c|c|}
\hline Assessment methods & Strongly Agree & Agree & Neutral & Disagree & Strongly Disagree \\
\hline $\begin{array}{l}\text { Did the Assessments in the form of formative } \\
\text { assessment serve the purpose of analyzing } \\
\text { cognitive skill (Knowledge)? }\end{array}$ & $22 \%$ & $46 \%$ & $24 \%$ & $5 \%$ & $3 \%$ \\
\hline $\begin{array}{l}\text { Do you think MCQs are an effective tool for } \\
\text { analyzing cognitive skills? }\end{array}$ & $34 \%$ & $40 \%$ & $21 \%$ & $5 \%$ & - \\
\hline
\end{tabular}

and $40 \%$ agree), while $21 \%$ of the students had a neutral opinion about this, and $5 \%$ of them did not agree with this. (Table 3)

Questions were asked on the adequacy of the existing number of lectures and changes in teaching methodology required if any. Of the 152 students, $78 \%$ felt the number of lectures was adequate, $14 \%$ of the students think that the number of pathology lectures was excess in quantity, and $8 \%$ felt the number of lectures was inadequate.

In the present study, $89 \%$ of students agreed that case-based learning must be included in the pathology curriculum; 8 $\%$ had a neutral opinion on it, while $3 \%$ disagreed with it. The majority (62\%) of the students agreed that small group discussions must be utilized for a better understanding of the subject; $28 \%$ have a neutral opinion on it, while $10 \%$ disagreed with it. Only $19 \%$ of the students had a positive response about pathology as a carrier option, while $52 \%$ had a neutral opinion, and $29 \%$ did not want to take up pathology as their career.

\section{DISCUSSION}

Pathology is a basic science subject that provides a scientific foundation for the human disease process in medical education. It is taught in the second year of undergraduate (MBBS) degree in India. The duration of the training is 18 months, including the examinations. Traditionally, the theory classes were conducted using PPP and blackboard (or whiteboard), whenever needed. Feedback from students is the right way of evaluation of a training program, and it would influence the quality of a teacher's future teaching skills. ${ }^{5,6}$

Our findings indicated that $84 \%$ of students perceived pathology as an interesting subject. This is similar to the study done by Vijayan $\mathrm{P}$ et $\mathrm{al}^{1}$, where $97 \%$ found the pathology subject interesting while 3\% disagreed. Similarly, in the survey conducted by Emerald NM2, 55\% found pathology interesting. Most of the students (60\%) strongly agreed that pathology helps in clinical training. In a study done by Shah AR et $\mathrm{al}^{5}, 86.6 \%$ of the students believed that understanding pathology helps them in clinical posting. By knowing the pathogenesis, students get a complete picture of the disease when he attends clinical postings.

In our study, $87 \%$ of students agreed that the integration of pathology teaching with clinical training helps in a better understanding of diseases. In a similar survey by SSS Quadri et $\mathrm{al}^{3}, 53 \%$ of students agreed while $17 \%$ disagreed. Similarly, $62 \%$ of the students agreed to integration in the study conducted by Wader $\mathrm{J}$ V et $\mathrm{al}^{4}$ and Kar A et al. ${ }^{6}$

The majority of students (32\%) agreed that general pathology is more difficult to understand than systemic pathology, whereas $22 \%$ of the students strongly agreed to it. According to a study done by Vijayan $\mathrm{P}$ et $\mathrm{al}^{1}, 65 \%$ of students found systemic pathology difficult than general pathology, while $28.3 \%$ found general pathology difficult. General pathology can be mastered by understanding the pathogenesis of diseases with strong cognitive skills. In contrast, systemic pathology, although vast, can be better understood by remembering the gross and microscopy of the conditions, many of which are also repeated in practical hours with an additional psychomotor domain. Furthermore, systemic pathology topics are more often integrated with clinical departments.

In the present study, we found that $40 \%$ of our study population agreed that lectures and demonstrations are taken in ways that generate interest in the subject while $28 \%$ disagreed. According to the study conducted by Vijayan $\mathrm{P}$ et $\mathrm{al}^{1}$ and Husain $\mathrm{M}$ et $\mathrm{al}^{7}$, similar results were obtained. Didactic lectures have few limitations, and as the strength of the class is 150 and more, it is challenging to gain attention and generate interest in the subject.

In our study, $53 \%$ of students were satisfied with the delivery and pace of lectures for a better understanding of the subject, while 11\% were dissatisfied, and $36 \%$ had a neutral opinion. Similarly, $68 \%$ agreed, and $25 \%$ disagreed with this in the study conducted by Vijayan $\mathrm{P}$ et al. ${ }^{1}$ The pace of lectures can always be improved for the interest of the students by keeping more pictures and flow charts in the slides hence reducing the matter.

In the present study, $46 \%$ agreed, $27 \%$ had a neutral opinion, and $18 \%$ strongly agreed that teaching of clinical correlation wherever relevant had been done in pathology lectures. A better understanding of pathology is ensured when the teacher adds on a few points about the clinical presentation of the disease by showing clinical photographs or gives a case-based history of the patient as students are exposed to patients during the clinical postings ${ }^{3}$. Early clinical exposures, which are a part of competency-based medical education, are an excellent concept to generate interest among the students. ${ }^{8}$ 
Pathology is a vast subject, and highlighting important points at the end of the class does help the students to focus on a specific important aspect of the topic, which is expected to be written in the exams. In our study, $71 \%$ were satisfied that important points had been adequately highlighted during lectures. Similarly, $93 \%$ agree to the same in the survey conducted by Vijayan P et al. ${ }^{1}$ Overall, $23 \%$ of the students strongly agreed, $37 \%$ agreed, $29 \%$ had a neutral opinion, and $11 \%$ disagreed that the teachers encouraged students to ask questions and give answers during lectures. In a study done by Quadri SSS et $\mathrm{al}^{3}, 40.1 \%$ of students agreed, $13.7 \%$ strongly agreed, $34.01 \%$ neutral, and 11.16 $\%$ disagreed that they were encouraged to ask questions and give answers during lectures. It is better to practice this in lectures as the students can clear their doubts about the topic, and the teacher is also ensured that students have understood the issue.

Regarding the teaching tools used in Pathology, 55\% of our students preferred teaching by PPP only while $45 \%$ preferred combined blackboard boards and PPP. In a study done by Kar A et $\mathrm{al}^{6}$, students preferred blackboard teaching $(36 \%)$ to the audiovisual mode $(6 \%)$ of teaching, and the majority, and $58 \%$ opted for a combined method of teaching. In a study done by Vamshi et $\mathrm{al}^{9}, 71 \%$ voted for 'chalk and talk' as a better and useful tool to explain subject efficiently, 67 thought it is better than PPP to create interest, 72 agreed that the chalk and talk have three basic components like "inspire, influence and inform" in a better way than PPP. The judicious use of audiovisual aids, along with the conventional methods, is necessary so that the power-point presentation should complement the teaching methodology.

In our study, many considered that integrated teaching helps in a better understanding of the subject. Quadri SSS et $\mathrm{al}^{3}$ in their research found that $76.64 \%$ of students strongly favoured the need for the introduction of integrated teaching in the curriculum. Similar findings were observed in the study by Shah AR et $\mathrm{al}^{5}$, Goyal et $\mathrm{al}^{10}$, and Kate et al. ${ }^{11}$ The integrated teachings enhance the skill of clinicopathological correlation and help to improve the cognitive and psychomotor domain of the students.

Assessment is considered the most important driving factor of student learning, as students tend to focus on the material to be assessed mainly. The type of assessment method adopted can influence student learning. In our study, most of the students strongly agreed that the assessments conducted in the form of the formative evaluation served the purpose of assessing knowledge. The results of our study agree with studies done by Vijayan P et al ${ }^{1}$ and Quadri SSS et al. ${ }^{3}$ In the present study, $74 \%$ of the students strongly believed that MCQs are an effective tool in assessing the cognitive domain. In a study done by Kar A et $\mathrm{al}^{6}$, the majority (78\%) approved that change in assessment in theory examination of students is necessary by including MCQs, short questions, and short answers instead of long questions. The majority also felt that it is beneficial when MCQ s are given in class after lectures. Multiple choice questions are an effective way to assess the students' knowledge, as some of the good students might be poor in framing answers. It increases the thinking capacity of students as there will be very strong distracters. Also, it is a scoring tool for students and consumes less time.

Overall, $78 \%$ feel the number of lectures was adequate, $14 \%$ of the students think that the number of pathology lectures was excess in quantity, and $8 \%$ felt the number of lectures was inadequate. Quadri SSS et $\mathrm{al}^{3}$ in their study also found that the number and duration of lectures were considered adequate by $55.84 \%$ and $63.95 \%$, respectively. Nagar SK et $\mathrm{al}^{12}$ also showed that the majority of the students believed that the lectures taken by the teachers were adequate. As per the new curriculum-based medical education (CBME), the didactic lectures should not exceed one-third of the schedule, and more time is allotted to small group teaching and self-directed learning. It is challenging to bring these changes to the curriculum and implement the same.

Case-based discussions and small group discussions were favored by $89 \%$ and $62 \%$ of our students, respectively. Similar results were seen in the study conducted by Vijayan $\mathrm{P}$ et $\mathrm{al}^{1}$ and Shah AR et $\mathrm{al}^{5}$. In a similar survey conducted by Vamshi et $\mathrm{al}^{9}$, it was concluded that technologyintensive instructional innovations like PPP did not cause increased student engagement in undergraduate classes, and traditional pedagogy was more effective.

Studies have shown that the attention span of an adult learner is $18-20$ minutes after that, there is a lapse. ${ }^{13}$ This problem can be very well taken care of, with interactive or activity-based sessions than the traditional passive methods of teaching. Problem-based learning is learner-centered rather than being problem-solving and teacher-centered. Studies have shown it to be effective in comparison with lecture-based education. ${ }^{14,15}$ Apart from this, 'Role Play' exercises can be used to enhance students' participation and hence learning. ${ }^{10}$

Regarding the question of whether the students would prefer to take pathology as a carrier option, only $19 \%$ had a positive response. In comparison, $52 \%$ had a neutral opinion, and $29 \%$ did not want to take it. This reflects the ignorance of the students about the prospects in pathology and also necessitates the need to explore ways to make the students aware of the opportunities in pathology.

\section{CONCLUSIONS}

While having a positive attitude towards pathology subject, and about the traditional lecture-based teaching, students 
felt that case-based discussions and integrated teaching are among the most effective ways for effective learning. With the new curriculum for medical education is on the cards, the result of our study is an encouragement to be prepared for the same. By implementing this, the awareness about pathology as a career can be improved.

\section{Conflict of interest: None}

\section{REFERENCES}

1. Vijayan P, Ponnaiah A. A survey study based on undergraduate medical students' feedback regarding pathology and the teaching-learning methodologies employed. Trop J Path Micro 2017; 3: 149-54. $\underline{\text { Crossref }}$

2. Emerald NM, Han T, Oo S S. Students' perception of the effectiveness of pathology teaching in phase 1 medical program at UCSI University. International journal of medical science and education 2016; 3: 264-73. Website

3. Quadri SSS, Srujana S, Mahesh S, et al. Undergraduate medical students' feedback and perceptions on teachinglearning methodology in Pathology at Government medical college. IAIM 2016; 3: 28-35. Website

4. Wader J V, Kumbhar SS, Mankar D V. An appraisal of innovation in practical teaching in anatomic pathology- a students' and teachers' perspective. Al Ameen J Med Sci 2014; 7:58-64. Website

5. Shah AR, Shethwala N, Parmar B. Perception of undergraduate medical students towards the subject of pathology at one of the medical colleges of Gujarat, India. International Journal of Medical Science and Public Health, 2014; 3:863-5. Crossref

6. Kar A, Kar T, Dash K, et al. Undergraduate pathology education: meeting the challenge ahead. International journal of clinical medicine 2012; 3:83-7. Crossref

7. Husain M, Khan S. Students' feedback: An effective tool in the teacher's evaluation system. International Journal of Applied and Basic Medical Research. 2016;6:178 Crossref

8. Early clinical exposure. ( Cited on 2/4/2020) Website

9. Vamshi KT, Datta VM, Kishan YSS, et al. Comparative study on the teaching effectiveness of chalk and talk and Microsoft PowerPoint presentation from the student perspective. Int $\mathrm{j}$ Pharm Pharm Sci. 2011; 4:191-3. Website

10. Goyal M, Bansal M, Gupta A, et al. Perceptions and suggestions of 2nd professional MBBS students about their teaching and learning process: An analytical study. NJIRM, 2010; 1: 20-4. Website
11. Kate MS, Kulkarni UJ, Supe A, et al. Introducing integrated teaching in undergraduate medical curriculum. International Journal of Pharma Sciences and Research. 2010;1:18-22. Website

12. Nagar SK, Malukar O, Kubavat D, et al. Students perception on anatomy teaching methodologies. Natl J. Med Res., 2012; 2:111-5. Website

13. Rhem J. The "Change-Up" in Lectures. The National Teaching and learning forum. Indiana University.1996 Jan; 5(2). Website

14. Vollebregt JA, van Oldenrijk J, Kox D, et al. Evaluation of a pharmacotherapy context- learning program for preclinical medical students. Br J Clin Pharmacol 2006; 62:666-72. Crossref

15. Majumder AA, D' Souza U, Rahman S. Trends in medical education: challenges and directions for need-based reforms of medical training in South East Asia. Ind J med sciences. 2004;27:153-157. Website 